\title{
Access to diphtheria antitoxin for therapy and diagnostics
}

L Both (Leonard.Both@phe.gov.uk)1, J White ${ }^{2}$, S Mandal'2, A Efstratiou ${ }^{1}$

1. WHO Reference Centre for Diphtheria and Streptococcal Infections, Public Health England, London, United Kingdom

2. Immunisation, Hepatitis and Blood Safety Department, Centre for Infectious Disease Surveillance and Control, Public Health England, London, United Kingdom

Citation style for this article:

Both L, White J, Mandal S, Efstratiou A. Access to diphtheria antitoxin for therapy and diagnostics . Euro Surveill. 2014;19(24):pii=20830. Available online: http:// www.eurosurveillance.org/ViewArticle.aspx?Articleld=20830

Article submitted on 29 January 2014 / published on 19 June 2014

The most effective treatment for diphtheria is swift administration of diphtheria antitoxin (DAT) with conjunct antibiotic therapy. DAT is an equine immunoglobulin preparation and listed among the World Health Organization Essential Medicines. Essential Medicines should be available in functioning health systems at all times in adequate amounts, in appropriate dosage forms, with assured quality, and at prices individuals and the community can afford. However, DAT is in scarce supply and frequently unavailable to patients because of discontinued production in several countries, low economic viability, and high regulatory requirements for the safe manufacture of blood-derived products. DAT is also a cornerstone of diphtheria diagnostics but several diagnostic reference laboratories across the European Union (EU) and elsewhere routinely face problems in sourcing DAT for toxigenicity testing. Overall, global access to DAT for both therapeutic and diagnostic applications seems inadequate. Therefore - besides efforts to improve the current supply of DAT - accelerated research and development of alternatives including monoclonal antibodies for therapy and molecular-based methods for diagnostics are required. Given the rarity of the disease, it would be useful to organise a small stockpile centrally for all EU countries and to maintain an inventory of DAT availability within and between countries.

\section{Background}

Diphtheria is an acute bacterial infection of pharynx, larynx, tonsils, nose and occasionally other mucous membranes or skin [1]. Initial symptoms include pharyngeal pseudomembrane formation or skin ulcers. In most industrialised countries diphtheria has largely been eliminated due to mass vaccination campaigns in the 1940 s and 1950 s and the widespread introduction of universal childhood immunisation with the combined tetanus-diphtheria-pertussis (DTP) vaccine [2]. While diphtheria is preventable by vaccination, the disease persists because of regional variations in compliance with vaccination, inadequate booster regimens and immunosenescence [3]. According to the World Health Organization (WHO), 4,500-5,500 cases were reported annually worldwide between 2011 and 2013, with the majority occurring in India and Indonesia [4]. Although most deaths occurred in disease-endemic countries, case-fatality rates were highest in countries where diphtheria is not endemic and where unfamiliarity with the disease can lead to delays in diagnosis and treatment [3].

In Europe, diphtheria incidence has decreased after resurgence in the 1990 shen it caused 157,000 cases and 5000 deaths in countries in the eastern part of the WHO European Region. Circulation has continued in some countries in eastern Europe and sporadic cases have been reported elsewhere across Europe. Surveillance data from countries participating in the European Diphtheria Surveillance Network and for the WHO European region for 2000 to 2009 suggest that diphtheria incidence had decreased by over $95 \%$ across the Region over 10 years, with the Russian Federation and Ukraine accounting for $83 \%$ of all cases [3]. A relatively small number of cases were identified in European Union (EU)/European Economic Association (EEA) countries; 20 cases were reported in 2011 according to the European Centre for Disease Prevention and Control (ECDC) annual epidemiological report [5]. Case numbers were particularly high in Latvia in both 2011 $(n=6)$ and $2012(n=8)$, although they were much lower than those reported in Latvia in $2008(n=29)$. According to WHO, Germany reported the highest number of diphtheria cases among all EU/EEA countries in $2012(n=9)$ [4].

The causative agents of diphtheria are toxigenic corynebacteria, namely $C$. diphtheriae, $C$. ulcerans and C. pseudotuberculosis [6]. If left untreated, the bacterial toxin can enter the circulation leading to cardiac and neurologic sequelae $[6,7]$. The key to effective treatment is swift administration of equine antiserum, commonly referred to as diphtheria antitoxin (DAT). Serum therapy was born in 1890 when Behring and Kitasato [8] showed that passive immunisation with tetanus and diphtheria antisera could protect against these bacterial diseases (Figure 1). In 1901, Behring 
Timeline of developments for diphtheria antitoxin used in therapy and diagnostics

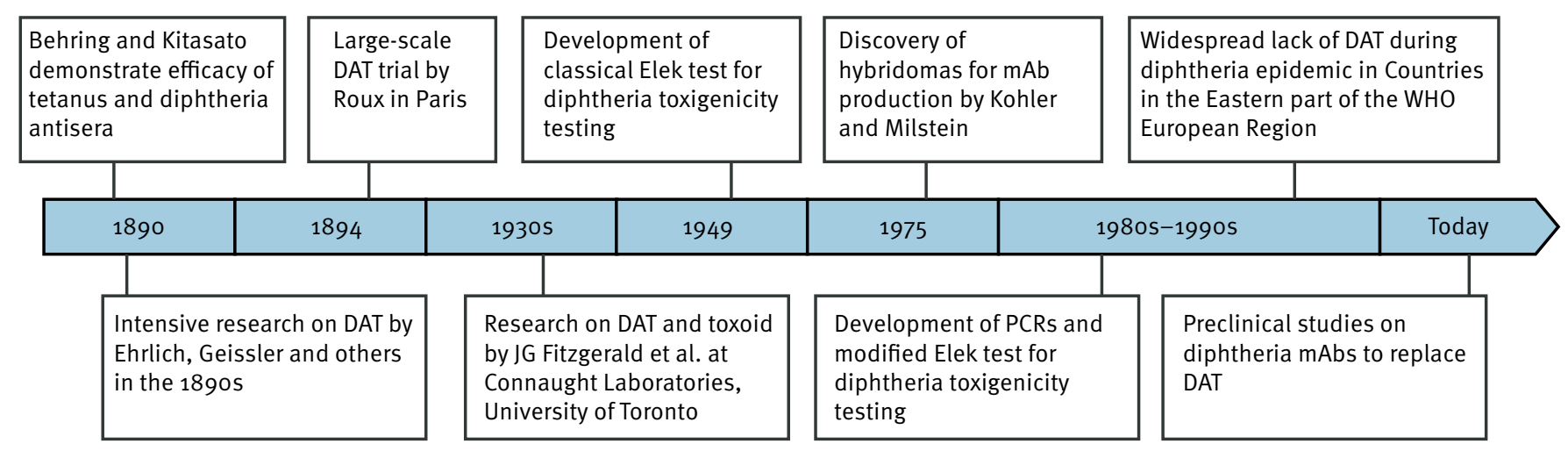

DAT: diphtheria antitoxin; mAB: Anti-diphtheria monoclonal antibodies; PCR: polymerase chain reaction, WHO: World Health Organisation. Behring and Kitasato's discoveries in 1980 marked the birth of passive immunisation.

received the first Nobel Prize in Physiology or Medicine for his contributions to the development of passive immunisation and serum therapy. Ehrlich later standardised the strength of DAT, defining one unit of DAT as the amount required to neutralise the minimum dose of toxin to kill a guinea pig [9,10]. The Germany-based company Hoechst produced DAT commercially and sponsored Behring's and Ehrlich's research that transformed DAT into an effective remedy for the disease [11]. Following Geissler's first successful DAT treatment of an infected child, Pasteur Institute scientist Emile Roux carried out a large-scale trial of DAT therapy in 1894 in Paris (Figure 1). This trial demonstrated distinct differences between the mortality rates in 448 treated children $(24,5 \%)$ and in 520 untreated children (60\%), respectively $[9,11]$.

Although the use of antibacterial sera was more common in the pre-antibiotic era and has become largely redundant today due to the widespread use of antibacterial vaccines (e.g. DTP vaccine) [12], a range of different sera/immunoglobulins are still in clinical use today, notably those included in the WHO Essential Medicines List. The list contains several antisera and immunoglobulins for passive immunisation, namely diphtheria antitoxin, anti-tetanus immunoglobulin, rabies immunoglobulin, and anti-venom immunoglobulin (Table 1). Essential medicines are intended to be available in functioning health systems at all times in adequate amounts, in appropriate dosage forms, with assured quality, and at prices individuals and the community can afford [13,14]. Identifying a list of essential medicines for healthcare needs of the population can support countries in prioritising the purchasing and distribution of medicines, thereby reducing costs to the health system. The availability of medicines may be compromised by several factors, including poor medicine supply and distribution systems, insufficient health facilities and staff, low investment in health and the high cost of medicines $[13,14]$.

In practice, DAT is administered following on an initial, presumptive clinical diagnosis, and is usually given as early as possible, even before the laboratory results for bacteriological confirmation are obtained [15]. DAT can only neutralise free toxin which has not yet bound to cells [15]. A Latvian study found DAT to be ineffective when administered after the second day of symptoms [16]. Administration of DAT is not uncomplicated since it is an equine derivative with a risk of acute and delayed hypersensitivity reactions [17].

Being aware of recent changes in production of DAT that could bring about a lack of antitoxin for treatment TABLE 1

Sera and immunoglobulins included in the World Health Organization Essential Medicines List for Children [13]

\begin{tabular}{|l|l|}
\hline Sera & \multicolumn{1}{|c|}{ Product characteristics } \\
\hline Diphtheria antitoxin (DAT) & Injection; 10,000 IU; 20,000 in vial $^{\text {a }}$ \\
\hline $\begin{array}{l}\text { Anti-rabies } \\
\text { immunoglobulin (human) }\end{array}$ & Injection; $150 \mathrm{IU} / \mathrm{ml}$ in vial \\
\hline $\begin{array}{l}\text { Anti-tetanus } \\
\text { immunoglobulin (human) }\end{array}$ & Injection; 500 IU in vial \\
\hline $\begin{array}{l}\text { Anti-venom } \\
\text { immunoglobulin }\end{array}$ & $\begin{array}{l}\text { Injection; exact type to be defined } \\
\text { locally }\end{array}$ \\
\hline
\end{tabular}

IU: international units.

a Dose may differ according to clinical presentation.

${ }^{b}$ Dose differs between treatment and prophylaxis.

The World Health Organization Essential Medicines List for Adults additionally contains Rho(D) Ig for prevention of Rhesus disease [14]. 
and diagnosis, and following discussions with several experts in this field about the ongoing lack of antitoxin access, we aimed to address the question if access and usage of diphtheria antitoxin was sufficient to guarantee high standards in therapy and diagnostics for diphtheria and how the perceived lack of access could potentially be overcome in the future.

\section{Literature research and results}

In order to find of evidence of access to DAT and its usage, a literature review (Figure 2) was performed during September to December 2013 and updated in January 2014. The focus of this non-systematic review was overall access to antitoxin, either for therapeutic purposes/passive immunisation or for diagnostic purposes/toxigenicity testing. We identified references for this review through searches in PubMed and Google Scholar databases with the terms 'diphtheria', 'antiserum', 'passive immunity/immunization', 'WHO Essential Medicines', and 'monoclonal antibodies'. Search was not restricted with respect to publication date or language. More specific searches were then undertaken with the terms 'diphtheria antitoxin administration' and 'diphtheria monoclonal antibodies'. The search yielded 208 and 306 articles, respectively. Fourty articles resulting from both the general and specific searches and relevant references cited in those articles met the criteria for topic or quality and were reviewed by all authors. All other articles screened initially were excluded from further analysis. We also included points raised in communications with several national competent authorities, e.g. the national diphtheria reference laboratories in the EU Member States, and points raised through communications via the ECDC Epidemic Intelligence Information System for VaccinePreventable Diseases (EPIS-VPD).

\section{Access to diphtheria antitoxin for therapy}

DAT has been the cornerstone of diphtheria treatment and diagnostic for many decades. However, several countries stopped manufacturing their own DAT supplies following the introduction of mass vaccination in the $1940 \mathrm{~s} / 50 \mathrm{~s}$ and the consequent decline in diphtheria cases $[18,19]$. Moreover, production for export in various countries was subsequently reduced or stopped, leading to outdated stockpiles in some countries and a total lack of product in others [19]. For example, companies in Australia, Poland and Switzerland that previously supplied several countries with DAT have ceased production in the past few years [19]. The lack of DAT was highlighted when a case of diphtheria was diagnosed in November 2008 in France, where production had been stopped in 2002, and when it took four days for DAT to be delivered from a manufacturer in Brazil after failed efforts to obtain this treatment from neighbouring countries [19]. This is of great concern, particularly when considering the requirement for early DAT administration when disease is suspected.

The current lack of access to DAT has also been flagged through ECDC's EPIS-VPDwhere several EU countries

\section{FIGURE 2}

Flowchart for literature search

General search for key words 'diphtheria', 'antiserum', 'passiveimmunity', 'WHO Essential Medicines', 'monoclonal antibodies'

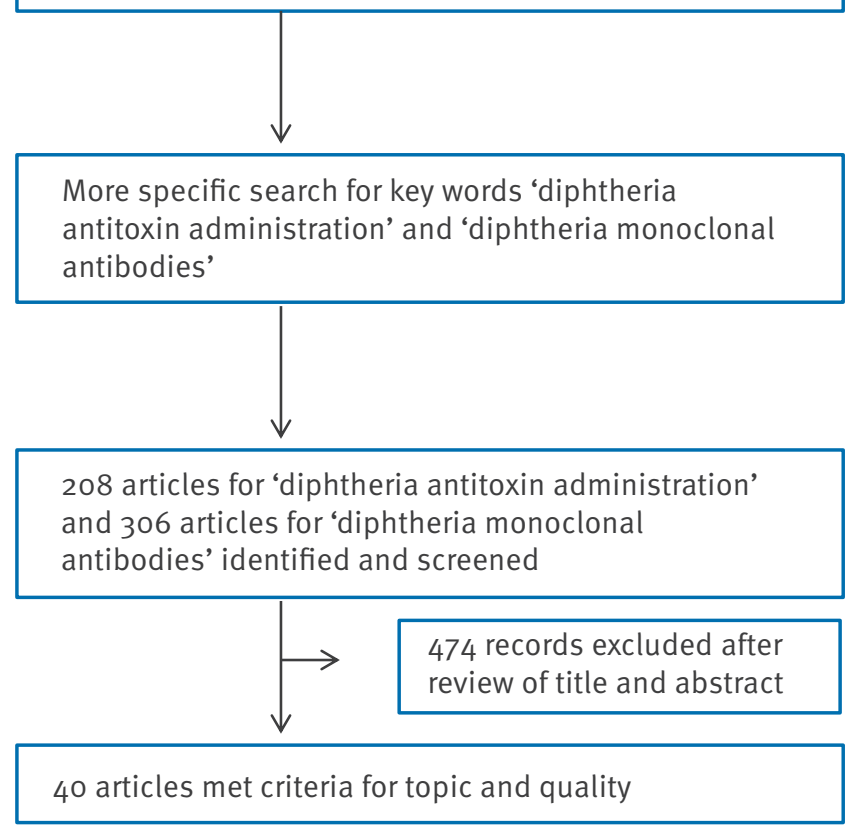

posted information in January 2014 that they have problems in re-stocking their current DAT supplies. For example, the United Kingdom (UK) is facing problems with sourcing their stock and is exploring alternative DAT sources, but all DAT products used in the UK first need to pass testing by the National Institute of Standards and Biological Controls (A. Efstratiou, personal communication). As in addition to the ones mentioned above, previous DAT suppliers, e.g. in Croatia and Brazil, are not manufacturing and cannot provide assurance that they will be soon, there are indeed only few international suppliers left, e.g. Vins Bioproducts, Hyderabad, India.

The current situation across Europe constitutes a risks that patients presenting with diphtheria have to recover without DAT, and marks a return to an era without passive immunisation as seen over 100 years ago before Behring and Kitasato's first experiments. Of note, the problems in sourcing DAT are not limited to Europe and it seems that the United States Centers for Disease Control (CDC), who previously procured DAT from Brazil, are also experiencing difficulties obtaining new stocks. Needless to say, the DAT supplies across many developing countries are also insufficient [19].

Access to diphtheria antitoxin for diagnostics In addition to its application in diphtheria therapy, DAT is also a cornerstone of diphtheria diagnosis. The Elek immunoprecipitation test visualises specific 
interactions between DAT and the bacterial toxin, thereby informing if a bacterial isolate expresses the toxin. The detection of toxigenicity among $C$. diphtheriae, $C$. ulcerans and $C$. pseudotuberculosis strains is the most important test for the microbiological diagnosis of diphtheria $[20,21]$. Stephen Elek first described this test in 1949 at St George's Hospital Medical School, London [20,21]. More recently, a modified Elek test was described which provides an accurate result after only $16 \mathrm{~h}$ of incubation, in contrast to $48 \mathrm{~h}$ for the conventional Elek test [22]. Additionally, polymerase chain reaction $(P C R)$ has been used for the rapid detection of the diphtheria toxin-encoding tox gene [23]. A range of different PCR assays for detection of the toxin gene are available and show close correlation with Elek test results and adenosine diphosphate (ADP)-ribosylation activity assays [24]. These PCR assays target either the toxin A fragment responsible for inhibiting protein synthesis, the toxin $B$ fragment responsible for binding the cellular receptor, or both domains using two set of primers in parallel [25]. More recently, several real-time PCRs have been developed to rapidly detect and simultaneously differentiate toxigenic $C$. diphtheriae and $C$. ulcerans strains [26,27]. However, isolates of $C$. diphtheriae which possess the toxin gene but which do not express a biologically active protein (and are therefore for diagnostic purposes non-toxigenic), named non-toxigenic tox-bearing (NTTB) strains, have been found [28]. Although such strains are relatively rare, $P C R$ alone cannot provide a 100 per cent definitive result; therefore the Elek test remains the gold standard of toxigenicity testing.

Several national reference laboratories across the EU routinely face problems in sourcing DAT for the Elek test, mainly due to the widespread lack of DAT manufacturers and suppliers, for example, DAT is also not produced any more in Poland and Romania. As part of a survey in 2012 by the European Diphtheria Surveillance Network, a dedicated surveillance network of the ECDC, a total of 10 out of 27 European reference laboratories indicated that they routinely face problems in obtaining DAT (unpublished results). As of early 2014, this number increased to 17 out of 29 national reference laboratories in the EU, Israel and Turkey (unpublished data). Most of these 17 reference centres relied on antitoxin supplied by the WHO Global Reference Centre for Diphtheria and Streptococcal Infections at Public Health England (PHE), London, UK, in order to be able to perform Elek tests. Only six of 29 national reference centres responded that they face no major problems in sourcing DAT, which was either produced in-house or commercially obtained. Another six national reference centres made no comment about their access to DAT, mainly because the Elek test was no longer performed, i.e. only PCR was used or no toxigenicity testing was done at all.

The need for diphtheria antitoxin alternatives The reasons for the dwindling supply of DAT are probably multifactorial, including low economic viability and high regulatory requirements for the safe manufacture of blood-derived products. As antisera are of animal origin, the fractions need to be screened and tested for the presence of infectious agents, and all plasma fractions should comply with the WHO requirements. In addition to compliance with WHO standards, DAT might need to comply with regional Good Manufacturing Practices (GMP) requirements, e.g. when imported into EU countries.

\section{Alternatives for diphtheria antitoxin therapy} There have been a number of attempts to address the depletion of traditional sources of equine DAT, including considerations to use serum from immunised human donors $[29,30]$. Research in Russia during the $1990 \mathrm{~s}$ epidemic, which peaked in 1995 with a reported 50,000 cases in the WHO European Region, found that in an emergency situation it is possible to select donors among convalescent patients for obtaining specific

TABLE 2

Anti-diphtheria monoclonal antibodies investigated in pre-clinical studies, June 2014

\begin{tabular}{|c|c|c|c|c|c|c|}
\hline $\mathrm{mAb}(\mathrm{s})$ & Human/murine & Antibody isotype & Derivation & Target on toxin & In vivo testing & Reference \\
\hline $\mathrm{mAb} 315 \mathrm{C}_{4}$ & Human & $\lg G_{1}$ & $\begin{array}{l}\text { Antibody secreting } \\
\text { cells isolated } \\
\text { directly from } \\
\text { immunised } \\
\text { volunteers }\end{array}$ & Fragment B & $\begin{array}{l}\text { Guinea pig } \\
\text { challenge }\end{array}$ & [36] \\
\hline \begin{tabular}{|l|} 
mAb DTD4 \\
mAb DTD8 \\
mAb DTD10 \\
mAb DTD76 \\
\end{tabular} & Human & All IgG & $\begin{array}{l}\text { Human antibody } \\
\text { library }\end{array}$ & Fragment B & Rabbit skin test & [35] \\
\hline $\begin{array}{l}\text { mAb B6 } \\
\text { mAb D8 } \\
\text { mAb G6 }\end{array}$ & Murine & All lgG2b & Hybridomas & $\begin{array}{l}\text { B6: Fragment } B \\
\text { D8:Fragments A and B } \\
\text { G6: Fragment A }\end{array}$ & $\begin{array}{l}\text { Guinea pig } \\
\text { challenge }\end{array}$ & [34] \\
\hline
\end{tabular}

Ig: immunoglobulins; mAb: Anti-diphtheria monoclonal antibodies.

Antibody potency has been assigned historically using either the cutaneous erythrogenic assay in rabbits or guinea pigs or the neutralisation of toxin in guinea pigs measured by delay of mortality for up to 96 hours. 
anti-diphtheria plasma and that they could be indeed considered as donors in an emergency situation [31].

More promising than the use of human antisera, however, is the use of mass-produced monoclonal antibodies (mAbs). Neutralising mAbs represent a promising alternative to traditionally used polyclonal products, and countries with chronic shortages of DAT would benefit greatly from their replacement. The use of mAbs could circumvent certain problems arising from the production of antiserum, including its extremely limited supply, high manufacturing costs, risks of hypersensitivity reactions associated with equine sera, and potential risks of contamination in blood-derived products [32].

The first anti-infective mAbs have recently obtained regulatory approval, against respiratory syncytial virus infections (Palivizumab) and against anthrax (ABthrax) [33]. The discovery of potent neutralising antibodies against the diphtheria toxin holds great promise as potential therapeutic. Several diphtheria antitoxin mAbs have been developed and investigated in preclinical studies (Table 2) [34-36]. In particular, a neutralising human mAb developed by Massachusetts Biologic Laboratories $(\mathrm{MBL})$ has proven highly efficacious and completely protected guinea pigs from diphtheria intoxication in an in vivo lethality model [36]. This mAb binds to the receptor-binding domain of diphtheria toxin, and physically blocks the toxin from binding to the putative receptor, the heparin-binding epidermal growth factor-like growth factor (HB-EBF) [36].

\section{Alternatives for diphtheria antitoxin for diagnostics}

In addition to their application in diphtheria therapy, mAbs could also replace DAT in diphtheria diagnostics; several toxigenicity tests using reporter-coupled mAbs have been developed, e.g. a dipstick assay was developed for the rapid phenotypic detection of diphtheria toxin in clinical isolates [37]. This assay does not rely on polyclonal DAT, but instead incorporates a colloidal gold-coupled mAb specific for the toxin molecule [37], while other similar assays make use of alkaline phosphatase-coupled or fluorescein isothiocyanatecoupled mAbs $[38,39]$.

In the future, mAbs would not necessarily replace DAT completely but the two products could also be used alongside each other.

\section{Conclusion}

Diphtheria continues to be a health threat and lack of access to DAT substantially increases the likelihood of mortality, highlighted recently in outbreaks in southeast Asia and also in the 1990s during the epidemic in the eastern part of the WHO European Region. In the aftermath of the latter, several national health authorities have attempted to maintain adequate DAT stockpiles to ensure access to DAT in the event of occurring diphtheria cases or even future diphtheria outbreaks.
However, global supply and access to DAT for both therapeutic as well as diagnostic application remains insufficient and this situation is unlikely to change in the near future. Consequently, it would be useful to create an inventory of DAT availability within and between countries and this could be facilitated by organisations such as ECDC or WHO. Moreover, it would be beneficial if a small stockpile of DAT was organised centrally for all European countries. With regards to securing a European stockpile, the authors suggest that one EU Member State could potentially be commissioned to act for others.

A barrier to addressing the lack of DAT so far is the perception of diphtheria as a low-priority disease in Europe and elsewhere; thus, diphtheria is currently not regarded as a public health priority. Nevertheless, ensuring adequate access to diphtheria therapy and diagnostics seems a worthwhile goal and might also constitute an important step to eventually try eradicating this disease, similar to previous efforts undertaken for e.g. polio eradication.

While DAT is part of the WHO Essential Medicines List and should therefore be available in functioning health systems at all times in adequate amounts, the dwindling supply poses a need for other options. Thus, useful alternatives including mAbs for therapy and PCR-based diagnostic methods are likely to play an increasing role in global health practices against diphtheria in the near future.

\section{Conflict of interest}

None declared.

\section{Authors' contributions}

LB did the search of published work and wrote the draft manuscript. JW, SM and AE provided suggestions and helped to identify relevant studies. All authors corrected and approved the final version.

\section{References}

1. Quick ML, Sutter RW, Kobaidze K, Malakmadze N, Strebel PM, Nakashidze R, et al. Epidemic diphtheria in the Republic of Georgia, 1993-1996: risk factors for fatal outcome among hospitalized patients. J Infect Dis. 2000;181(1):130-7. http:// dx.doi.org/10.1086/315550

2. Popovic T, Mazurova IK, Efstratiou A, Vuopio-Varkila J, Reeves MW, De Zoysa A, et al. Molecular epidemiology of diphtheria. J Infect Dis. 2000;181 Suppl 1:S 168-77.

3. Wagner KS, White JM, Lucenko I, Mercer D, Crowcroft NS, $\mathrm{Neal} S$, et al. Diphtheria in the postepidemic period, Europe, 2000-2009. Emerg Infect Dis. 2012;18(2):217-25. http://dx.doi. org/10.3201/eid1802.110987

4. World Health Organization (WHO). Immunization surveillance, assessment and monitoring. Last updated 27 Feb 2014. Geneva: WHO. [Accessed 10 Oct 2013]. Available from: http:// www.who.int/immunization_monitoring/diseases/diphteria/ en/index.html

5. European Centre for Disease Prevention and Control (ECDC). Annual Epidemiological Report 2013. Stockholm: ECDC; 2013. [Accessed 10 June 2014] Available from: http://www.ecdc.europa.eu/en/ publications/_layouts/forms/Publication_DispForm. aspx? List=4f55ad51-4aed-4d32-b96o-af70113dbb9o\&ID=989 
6. Dorella FA, Pacheco LG, Oliveira SC, Miyoshi A, Azevedo V. Corynebacterium pseudotuberculosis: microbiology, biochemical properties, pathogenesis and molecular studies of virulence. Vet Res. 2006;37(2):201-18. http://dx.doi. org/10.1051/vetres:2005056

7. Wagner KS, White JM, Neal S, Crowcroft NS, Kuprevičiene N, Paberza R, et al. Screening for Corynebacterium diphtheriae and Corynebacterium ulcerans in patients with upper respiratory tract infections 2007-2008: a multicentre European study. Clin Microbiol Infect. 2011;17(4):519-25. http://dx.doi. org/10.1111/j.1469-0691.2010.03269.x

8. Behring E, Kitasato S. Über das Zustandekommen der Diphtherie-Immunität und der Tetanus-Immunität bei Thieren, 1890 [The mechanism of diphtheria immunity and tetanus immunity in animals. 1890]. Mol Immunol. 1991;28(12):1317, 1319-20. German.

9. Schwartz RS. Paul Ehrlich's magic bullets. N Engl J Med. 2004;350(11):1079-80. http://dx.doi.org/10.1056/NEJMp048021

10. Park WH, Atkinson JP. The relation of the toxicity of diphtheria toxin to its neutralizing value upon antitoxin at different stages in the growth of culture. J Exp Med. 1898;3(4-5):513-32. http:// dx.doi.org/10.1084/jem.3.4-5.513

11. Linton DS. Emil von Behring: Infectious Disease, Immunology, Serum Therapy. Philadelphia: American Philosophical Society, 2005.

12. Casadevall A, Dadachova E, Pirofski LA. Passive antibody therapy for infectious diseases. Nat Rev Microbiol. 2004;2(9):695-703. http://dx.doi.org/10.1038/nrmicro974

13. World Health Organization (WHO). WHO Model Lists of Essential Medicines. Geneva: WHO. [Accessed 10 Oct 2013]. Available from: http://www.who.int/medicines/publications/ essentialmedicines/en/

14. World Health Organization (WHO). Essential medicines. [Accessed 10 Oct 2013]. Available from: http://www.who.int/ medicines/services/essmedicines_def/en/index.html

15. Begg, N. Manual for the Management and Control of Diphtheria in the European Region. Expanded Programme on Immunization. Copenhagen: WHO; 1994

16. Logina I, Donaghy M. Diphtheritic polyneuropathy: a clinical study and comparison with Guillain-Barré syndrome. J Neurol Neurosurg Psychiatry. 1999;67(4):433-8. http://dx.doi. org/10.1136/jnnp.67.4.433

17. Wilde H, Thipkong P, Sitprija V, Chaiyabutr N. Heterologous antisera and antivenins are essential biologicals: perspectives on a worldwide crisis. Ann Intern Med. 1996;125(3):233-6. http://dx.doi.org/10.7326/0003-4819-125-3-199608010-00012

18. From the Centers for Disease Control and Prevention. Availability of diphtheria antitoxin through an investigational new drug protocol. JAMA. 1997;277(21):1665. http://dx.doi. org/10.1001/jama.1997.03540450021010

19. Wagner KS, Stickings P, White JM, Neal S, Crowcroft NS, Sesardic D, et al. A review of the international issues surrounding the availability and demand for diphtheria antitoxin for therapeutic use. Vaccine. 2009;28(1):14-20. http://dx.doi.org/10.1016/j.vaccine.2009.09.094

20. Elek SD. The plate virulence test for diphtheria. J Clin Pathol. 1949;2(4):250-8. http://dx.doi.org/10.1136/jcp.2.4.250

21. Young PS, Smith DD. The detection of toxin production by Corynebacterium diphtheriae in diagnostic laboratories. Pathology. 1976;8(2):101-4. http://dx.doi. org/10.3109/00313027609094434

22. Engler KH, Glushkevich T, Mazurova IK, George RC, Efstratiou A. A modified Elek test for detection of toxigenic corynebacteria in the diagnostic laboratory. J Clin Microbiol. 1997;35(2):495-8.

23. Pallen MJ, Hay AJ, Puckey LH, Efstratiou A. Polymerase chain reaction for screening clinical isolates of corynebacteria for the production of diphtheria toxin. J Clin Pathol. 1994;47(4):353-6. http://dx.doi.org/10.1136/jcp.47.4.353

24. Hauser D, Popoff MR, Kiredjian M, Boquet P, Bimet F. Polymerase chain reaction assay for diagnosis of potentially toxinogenic Corynebacterium diphtheriae strains: correlation with ADP-ribosylation activity assay. J Clin Microbiol. 1993;31(10):2720-3.

25. Nakao H, Popovic T. Development of a direct PCR assay for detection of the diphtheria toxin gene. J Clin Microbiol. 1997;35(7):1651-5.

26. Schuhegger R, Lindermayer M, Kugler R, Heesemann J, Busch $U$, Sing A. Detection of toxigenic Corynebacterium diphtheriae and Corynebacterium ulcerans strains by a novel real-time PCR. J Clin Microbiol. 2008;46(8):2822-3. http://dx.doi. org/10.1128/JCM.01010-08

27. Sing A, Berger A, Schneider-Brachert W, Holzmann T, Reischl $U$. Rapid detection and molecular differentiation of toxigenic Corynebacterium diphtheriae and Corynebacterium ulcerans strains by LightCycler PCR. J Clin Microbiol. 2011;49(7):2485-9. http://dx.doi.org/10.1128/JCM.00452-11

28. Groman N, Cianciotto N, Bjorn M, Rabin M. Detection and expression of DNA homologous to the tox gene in nontoxigenic isolates of Corynebacterium diphtheriae. Infect Immun. 1983;42(1):48-56.

29. Sgouris JT, Volk VK, Angela F, Portwood L, Gottshall RY. Studies on diphtheria immune globulin prepared from outdated human blood. Vox Sang. 1969;16(6):491-5. http://dx.doi. org/10.1111/j.1423-0410.1969.tbo4777.x

30. Hartman LJ. Bioavailability study of diphtheria immunoglobulin (human). Pathology. 1979;11(3):385-7. http://dx.doi. org/10.3109/00313027909059015

31. Bissumbhar B, Rakhmanova AG, Berbers GA, lakolev A, Nosikova E, Melnick O, et al. Evaluation of diphtheria convalescent patients to serve as donors for the production of anti-diphtheria immunoglobulin preparations. Vaccine. 2004;22(15-16):1886-91. http://dx.doi.org/10.1016/j. vaccine.2003.11.006

32. Both L, Banyard AC, van Dolleweerd C, Wright E, Ma JK, Fooks AR. Monoclonal antibodies for prophylactic and therapeutic use against viral infections. Vaccine. 2013;31(12):1553-9. http://dx.doi.org/10.1016/j.vaccine.2013.01.025

33. Reichert JM. Marketed therapeutic antibodies compendium. MAbs. 2012;4(3):413-5. http://dx.doi.org/10.4161/mabs.19931

34. Danelli M das G, Teixeira LM, Formiga LC, Peralta JM. Protective monoclonal antibodies to diphtheria toxin. Mem Inst Oswaldo Cruz. 1991;86(2):265-7. http://dx.doi.org/10.1590/ So074-02761991000200017

35. Kakita M, Takahashi T, Komiya T, Iba Y, Tsuji T, Kurosawa Y, et al. Isolation of a human monoclonal antibody with strong neutralizing activity against diphtheria toxin. Infect Immun. 2006;74(6):3682-3. http://dx.doi.org/10.1128/IAI.01731-05

36. Sevigny LM, Booth BJ, Rowley KJ, Leav BA, Cheslock PS, Garrity $\mathrm{KA}$, et al. Identification of a Human Monoclonal Antibody to Replace Equine Diphtheria Anti-toxin for the Treatment of Diphtheria Intoxication. Infect Immun. 2013;81(11):3992-4000. http://dx.doi.org/10.1128/IAl.00462-13

37. Engler KH, Efstratiou A, Norn D, Kozlov RS, Selga I, Glushkevich TG, et al. Immunochromatographic strip test for rapid detection of diphtheria toxin: description and multicenter evaluation in areas of low and high prevalence of diphtheria. J Clin Microbiol. 2002;40(1):80-3. http://dx.doi.org/10.1128/ JCM.40.1.80-83.2002

38. Hallas G, Harrison TG, Samuel D, Colman G. Detection of diphtheria toxin in culture supernates of Corynebacterium diphtheriae and $C$. ulcerans by immunoassay with monoclonal antibody. J Med Microbiol. 1990;32(4):247-53. http://dx.doi. org/10.1099/00222615-32-4-247

39. Engler KH, Efstratiou A. Rapid enzyme immunoassay for determination of toxigenicity among clinical isolates of corynebacteria. J Clin Microbiol. 2000;38(4):1385-9. 